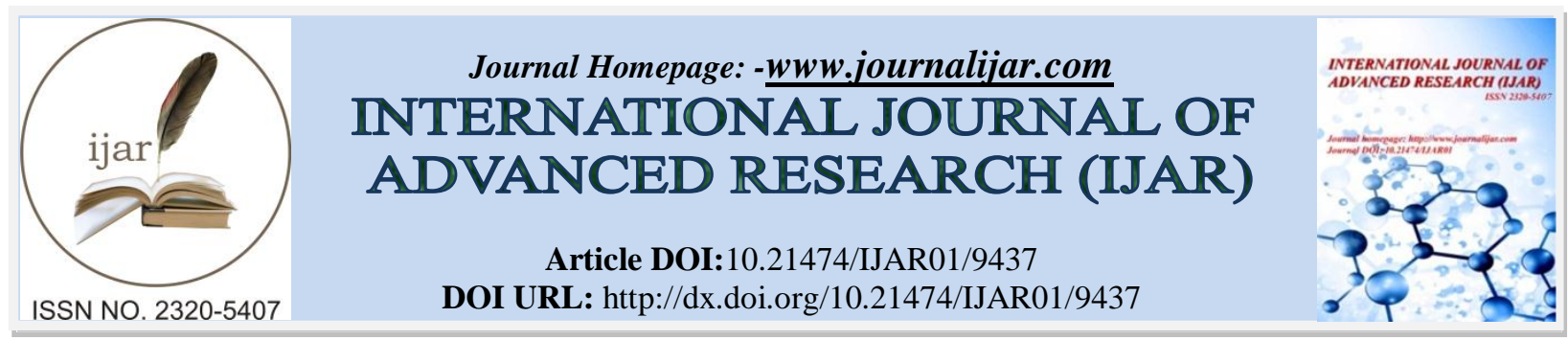

RESEARCH ARTICLE

\title{
COMPARISON OF NITRIC OXIDE AND MDA LEVELS IN TRAINED AND UNTRAINED INDIVIDUALS AT REST AND AFTER ACUTE MODERATE EXERCISE.
}

\section{Monica Verma ${ }^{1}$, Rajesh Kumar ${ }^{2}$, Kiran Dahiya ${ }^{3}$, Abhishek Soni ${ }^{4}$, Veena Singh Ghalaut ${ }^{5}$, Satpal ${ }^{6}$ and Ramesh} Sindhu? ${ }^{7}$.

1. Assistant Professor, Department of Biochemistry, Pt. B.D. Sharma, University of Health Sciences, Rohtak, Haryana- India.

2. Demonstrator, Department of Biochemistry, Kalpana Chawla Medical college, Karnal, Haryana- India.

3. Professor, Department of Biochemistry, Pt. B.D. Sharma, University of Health Sciences, Rohtak, HaryanaIndia.

4. Assistant Professor, Department of Radiotherapy, Pt. B.D. Sharma, University of Health Sciences, Rohtak, Haryana- India.

5. Senior Professor and Head, Department of Biochemistry, Pt. B.D. Sharma, University of Health Sciences, Rohtak, Haryana- India.

6. Athletic Coach, Maharishi Dayanand University, Rohtak,Haryana- India.

7. Lab Technician, Department of Biotechnology and Molecular Medicine, Pt. B.D. Sharma, University of Health Sciences, Rohtak, Haryana- India.

\section{Manuscript Info}

Manuscript History

Received: 24 May 2019

Final Accepted: 26 June 2019

Published: July 2019

Key words:-

nitric oxide, malondialdehyde, exercise, endurance training, trained athletes.

\section{Abstract}

Introduction: Exercise is a stress like condition resulting in increase of reactive oxygen species (ROS), but if done regularly strengthens the antioxidant system.During the past few decades, information about the biological implications of exercise-induced oxidative stress has expanded rapidly.

Aims And Objectives: No studies are available in literature to comment upon the levels of NO and MDA after acute moderate exercise. Therefore, we planned this study to compare the levels of NO and MDA in trained athletes and untrained healthy controls at rest and after 30 minutes of acute moderate exercise.

Materials And Methods: Study was conducted on fifty athletes who do regular sports activities and are healthy. Blood was collected before and immediately after acute exercise for estimation of NO and MDA by Griess reaction and Thiobarbituric acid reactive species (TBARS) method respectively. Data was analyzed by student's paired t test.

Results And Observations: Research findings indicate that there were statistically significant differences in the levels of TG, TC, LDL-C, HDL-C, NO and MDA post-exercise as compared to the pre-exercise levels in athletic group $(\mathbf{p}=0.02,0.03,0.03,0.02,0.005$, and 0.03 , respectively). There was no significant change in the levels of these variables in the control group before and after exercise. Pre-exercise values of TG, TC, LDL-C, HDL-C and MDA in trained athletes were lower than pre-exercise values in untrained group and the difference

Corresponding Author:-Monica Verma.

Address:-Assistant Professor, Department of Biochemistry, Pt. B.D. Sharma, University of Health Sciences, Rohtak, Haryana- India. 
was significant statistically $(\mathrm{p}=0.03,0.02,0.04,0.02$ and 0.03 respectively).

Conclusion: Acute moderate exercise in untrained individuals produces increased oxidative stress but after endurance training it has beneficial effects.

Copy Right, IJAR, 2019,. All rights reserved.

\section{Introduction:-}

Exercise causes an imbalance between oxidant and antioxidant system of our body. Exercise is a stress like condition resulting in increase in reactive oxygen species (ROS) but if done regularly it may strengthen the antioxidant system of the body. [1] During the past few decades, information about the biological implications of exercise-induced oxidative stress has expanded rapidly. Both resting and skeletal muscles produce ROS and reactive nitrogen species (RNS) which produce damage to both proteins and lipids in skeletal muscles. These might also play a role in regulating the expression of various genes responsible for antioxidant enzymes, DNA (deoxy ribonucleic acid) repair proteins, mitochondrial electron transport chain proteins, stress proteins etc. [2]

Nitric oxide (NO) is a lipophilic, highly diffusible physiological messenger with very short half life. It is synthesized by 3 different nitric oxide synthase (NOS) - neuronal NOS (nNOS or NOS-1), inducible NOS (iNOS or NOS-2) and endothelial NOS (eNOS or NOS-3) [3]. The increase in NO results in vasodilatation occurring during exercise and may prove beneficial for patients with vascular diseases. On the other hand, it being a free radical acts as a marker of oxidative stress also. Increased production of NO when react with different oxygen metabolites induces the synthesis of RNS [1].

Malondialdehyde (MDA) is the most frequently used marker of lipid peroxidation. It is a 3-carbon, low molecular weight aldehyde produced by free radical-mediated chain of reactions. Studies have shown increased levels of MDA after exercise as a state of increased oxidative stress. [4] The exercising muscles undergo ischemia reperfusion phenomenon resulting in generation of free radicals. This might differ in persons who are on regular athletic training programme as compared to untrained ones. No studies are available in literature to comment upon the levels of NO and MDA after acute moderate exercise. Therefore, we planned this study to compare the levels of NO and MDA in trained athletes and untrained healthy controls at rest and after 30 minutes of acute moderate exercise.

\section{Material And Methods:-}

The study was conducted in the Department of Biochemistry, Pt B D Sharma, University of Health Sciences, Rohtak in collaboration with Department of Physical Education, Maharishi Dayanand University, Rohtak. Fifty healthy athletes who do regular sports activities were enrolled in this study. All of them were studying in different colleges affiliated under the University. For comparison 50 age and sex matched healthy untrained adults from general population were enrolled as controls. Subjects with history of previous surgery or any chronic illness were excluded. Subjects suffering from any acute illness, with family history of any chronic illness or who were on any type of drug treatment were also excluded from the study. An informed consent was signed by each one of them. Detailed history including height, weight and waist circumference, duration of training, blood group and diet was taken. A digital weighing scale that could measure to the nearest $0.1 \mathrm{~kg}$ was used to record weight, and height was measured to the nearest centimeter using a measuring tape. Blood pressure was recorded using mercury sphygmomanometer with the subject in sitting posture. Blood was collected for baseline parameters from all of them in plain red colored vacutainers. Subjects were then asked to perform moderate exercise in the form of running on $400 \mathrm{~m}$ racing track for a duration of 30 minutes. Another blood sample was collected along with blood pressure measurement immediately after acute moderate exercise. Serum was separated after keeping the samples for 20 minutes. Serum was analyzed for estimation of lipid profile, NO and MDA. The NO level (measured as nitrite-plusnitrate $(\mathrm{NO}(\mathrm{x}))$ concentration) was estimated by Griess reaction. In this method nitrite reacts under acidic conditions with sulfanilic acid $\left(\mathrm{HO}_{3} \mathrm{SC}_{6} \mathrm{H}_{4} \mathrm{NH}_{2}\right)$ to form a diazonium cation $\left(\mathrm{HO}_{3} \mathrm{SC}_{6} \mathrm{H}_{4}-\mathrm{N} \mathrm{N} \mathbf{N}\right)$ which subsequently couples to the aromatic amine 1-naphthylamine $\left(\mathrm{C}_{10} \mathrm{H}_{7} \mathrm{NH}_{2}\right)$ to produce a red-violet coloured $(\lambda \max \approx 540$ nm), water-soluble azo dye $\left(\mathrm{HO}_{3} \mathrm{SC}_{6} \mathrm{H}_{4}-\mathrm{N} \mathrm{N}-\mathrm{C}_{10} \mathrm{H}_{6} \mathrm{NH}_{2}\right)$ [5]. MDA was assayed by colorimetric method using the principle that 2thiobarbituric acid (TBA) reacts with MDA when heated at acid pH. The optical density of the complex TBA-MDA was then recorded spectrophotometrically at $535 \mathrm{~nm}$. [6]. 
All statistical analyses were performed using the Statistical Package for the Social Sciences (SPSS) version 20 for windows. Values shown in the text, tables and figures are mean \pm SD. Paired student's $t$ test was applied for comparison of means of study groups. $p$ value $<0.05$ was considered significant and $<0.01$ as highly significant. Correlations between groups were analyzed using Pearson correlation coefficient ( $\mathrm{r}$ ) formula.

\section{Results:-}

The physical characteristics of all the subjects are presented in table 1. All athletes were undergoing training for a duration ranging from 6 months to 3 years. Comparison of within group differences of research variables are presented in Table 2. Research findings indicate that there were statistically significant differences in the levels of TG (Triglycerides), TC (Total cholesterol), LDL-C (Low density cholesterol), HDL-C (High density cholesterol), $\mathrm{NO}$ and MDA post-exercise as compared to the pre-exercise levels in athletic group $(\mathbf{p}=0.02,0.03,0.03,0.02$, 0.005 , and 0.03 , respectively). There was no significant change in the levels of these variables in the control group before and after exercise. Pre-exercise values of TG, TC, LDL-C, HDL-C and MDA in trained athletes were lower than pre-exercise values in untrained group and the difference was significant statistically $(\mathrm{p}=0.03,0.02,0.04,0.02$ and 0.03 respectively).

\section{Discussion:-}

The objective of this study was to determine the effect of acute moderate exercise on MDA and NO levels in trained athletes and to see the relationship with healthy untrained controls.

In this study, it was observed that the baseline serum MDA levels in trained athletes were significantly lower as compared to untrained athletes. This result is consistent with the previous study in which yoga exercise over a period of 12 weeks decreased plasma MDA levels reflecting reduced oxidative stress levels. [7] The MDA levels remained almost same in trained athletes but increased in untrained healthy control groups after acute 30 minutes running which indicates increased lipid peroxidation in untrained group. First confirmation for this was provided in 1970s by Brady et al. [8] and Dillard et al. [9] who reported an increased lipid peroxidation during exercise in both rats and humans which was further confirmed by many studies. [10-13] The degree of oxidation is determined by the type, duration and intensity of exercise. Respiration of mitochondria is increased with intensity of exercise producing oxygen free radicals which causes oxidation of PUFAs (Polyunsaturated fatty acids) of membrane. Therefore, after acute exercise the lipid peroxidation products determined by serum MDA levels were found increased in untrained healthy controls. But with long term aerobic training, the antioxidant capacity of our body increases thereby maintaining the balance between oxidant and antioxidant system and thereby decreasing the lipid peroxidation. [7]

A decrease in blood pressure was observed after aerobic training exercise showing antihypertensive role of training. This is due to decreased activity of rennin angiotensin system and sympathetic system. Also, increased NO levels (vasodilation) and decreased peripheral resistance are responsible for decrease in blood pressure as compared to control group. [14]

During endurance training repetitive contraction and relaxation of muscles leads to a variety of physiological and phenotypic changes like activation of mitochondrial biogenesis, fiber type transformation and angiogenesis. All these factors results in increased capacity of muscles to aerobic metabolism and its resistance to fatigue. Exercise induced increase in catecholamine levels also play a role in generation of ROS. [15] Although ROS and RNS produced during exercise produce several deleterious effects to tissues but regular exercise might have positive effects too by altering cellular processes to increase antioxidant production. [16]

The levels of NO tended to increase after endurance training. The levels further increased after running for 30 minutes in both the trained athletes and the untrained healthy controls. Results of this study are supported by various other studies who demonstrated an increase in NOS activity by, the indirect indices such as increased NO concentration in expired air [17] and increased urinary nitrates and cGMP (cyclic guanosine monophosphate) production. [18-20] NO is generated continuously by skeletal muscles and its synthesis further increases with exercise by increasing NOS activity. Skeletal muscles normally express eNOS (localized to muscle mitochondria) and nNOS (mainly expressed by fast twitch muscle fibers). [2] Roberts and Barnard reported $40 \%$ increase in NOS levels after exercise. [21] Hirschfield W demonstrated by his experiment that nNOS is the prime source of increased NO in exercising skeletal muscles. [22] Passive stretching of muscles has also been shown to increase NO levels in rat skeletal muscles in vitro. [23] But animal studies have reported increased eNOS mRNA in dog aorta and eNOS 
protein in rat aorta. [24, 25] Even the study done by Tanabe et al also reported an increase in eNOS [26]. The exact mechanisms by which NO levels are increased are still not known. Many people have given different hypothesis. Maeda S and colleagues proposed that regular training in healthy older humans decreases the concentration of plasma endothelin-1 (ET-1) which is a potent vasoconstrictor peptide produced by endothelial cells. Decrease in ET1 production contributes to increase NO levels as the two pathways engage in cross talk [27]. Also, endurance training leads to stretching of endothelial cells which may enhance sheer stress induced production of eNOS thereby enhancing the production of NO after chronic exercise. Lipid parameters also indirectly affect NO levels. LDL and TG have been shown to decrease NO dependent vasodilatation whereas HDL-C enhances eNOS protein expression in cultured human vascular endothelial cells. [27] In the present study TG and LDL-C levels decreased significantly with increased HDL-C levels after endurance training as compared to healthy untrained controls. So, metabolic changes also indirectly affect NO levels.

Endurance training results in homesis- paradoxical situation in which potentially harmful agents produce beneficial results. So, exercise induced oxidative stress in addidtion to providing adaptation to ROS provides improved physiological response and improved quality of life. Regular and continuous exercise training would effectively improve body composition by decreasing MDA and increasing NO levels in the body. Early studies focused on only oxidative damage produced by raised NO and MDA levels but increased free radicals do have many beneficial biological roles by controlling numerous redox sensitive transcription factors and modulating antioxidant status of body. But without regular exercise the raised ROS may prove harmful.

There are some limitations of this study. Firstly, we didn't measure other parameters of lipid peroxidation in particular 4-hydroxynonenal which is involved on one side in DNA damage and on other side regulates cell proliferation, growth and gene expression. Secondly, antioxidant levels were not analyzed.

\section{Conclusion:-}

Acute moderate exercise in untrained individuals produces increased oxidative stress but produces beneficial effects after endurance training.

Table 1:-Participant characteristics of the athletes and control group

\begin{tabular}{|l|l|l|}
\hline Parameter & Athlete group & Control group \\
\hline Age (years) & $17.6 \pm 3.08$ & $18 \pm 2.1$ \\
\hline M:F & $14: 1$ & $14: 1$ \\
\hline Height (meter) & $170 \pm 7.16$ & $171 \pm 3.2$ \\
\hline Weight (Kg) & $57.23 \pm 8.63$ & $56.76 \pm 2.7$ \\
\hline Waist circumference (cm) & $29.64 \pm 1.48$ & $35.4 \pm 2.12$ \\
\hline BMI $\left(\right.$ Kg/m $\left.{ }^{2}\right)$ & $19.8 \pm 1.98$ & $19.4 \pm 1.81$ \\
\hline Veg: Non-veg & $20: 30$ & $21: 29$ \\
\hline
\end{tabular}

Table 2:-The results of paired $\mathbf{t}$ test in athletes and control group before and after the acute moderate exercise.

\begin{tabular}{|c|c|c|c|c|c|}
\hline Parameter & Phase & Athlete group & p value & Control group & p value \\
\hline \multirow[t]{2}{*}{ SBP (mmHg) } & Pre-exercise & $110 \pm 1.20 *$ & \multirow[t]{2}{*}{0.61} & $128.5 \pm 9.9$ & \multirow[t]{2}{*}{0.82} \\
\hline & Post-exercise & $112 \pm 0.45$ & & $122.52 \pm 9.9$ & \\
\hline \multirow[t]{2}{*}{ DBP (mmHg) } & Pre-exercise & $70 \pm 0.91 *$ & \multirow[t]{2}{*}{0.03} & $81.65 \pm 5.0$ & \multirow[t]{2}{*}{0.56} \\
\hline & Post-exercise & $65 \pm 0.25$ & & $76.5 \pm 5.2$ & \\
\hline \multirow[t]{2}{*}{ TG (mg/dL) } & Pre-exercise & $128.08 \pm 23.8^{*}$ & \multirow[t]{2}{*}{0.02} & $160.8 \pm 24.6$ & \multirow[t]{2}{*}{0.65} \\
\hline & Post-exercise & $113.0 \pm 22.8$ & & $160.3 \pm 17.2$ & \\
\hline \multirow[t]{2}{*}{ TC (mg/dL) } & Pre-exercise & $169.10 \pm 23.8^{*}$ & \multirow[t]{2}{*}{0.03} & $194.8 \pm 27.6$ & \multirow[t]{2}{*}{0.75} \\
\hline & Post-exercise & $156.86 \pm 24.3$ & & $197.3 \pm 23.7$ & \\
\hline \multirow[t]{2}{*}{ LDL-C (mg/dL) } & Pre-exercise & $100.05 \pm 13.1^{*}$ & \multirow[t]{2}{*}{0.03} & $120.7 \pm 13.4$ & \multirow[t]{2}{*}{0.93} \\
\hline & Post-exercise & $94.29 \pm 14.25$ & & $119.3 \pm 13.1$ & \\
\hline \multirow[t]{2}{*}{ HDL-C (mg/dL) } & Pre-exercise & $35.04 \pm 3.21 *$ & \multirow[t]{2}{*}{0.02} & $34.56 \pm 6.7$ & \multirow[t]{2}{*}{0.87} \\
\hline & Post-exercise & $45.86 \pm 4.2$ & & $35.23 \pm 3.2$ & \\
\hline \multirow[t]{2}{*}{$\mathrm{NO}(\mu \mathrm{mol} / \mathrm{L})$} & Pre-exercise & $17.15 \pm 3.03^{*}$ & \multirow[t]{2}{*}{0.005} & $13.33 \pm 0.21$ & \multirow[t]{2}{*}{0.68} \\
\hline & Post-exercise & $18.30 \pm 3.54$ & & $18.0 \pm 1.21$ & \\
\hline MDA (mmol/L) & Pre-exercise & $3.24 \pm 1.17 *$ & 0.056 & $5.04 \pm 0.12$ & 0.76 \\
\hline
\end{tabular}




\section{Post-exercise}

$3.67 \pm 0.21$

$7.5 \pm 0.81$

*Significant results when compared to pre exercise values in control group.

SBP: Systolic blood pressure; DBP: Diastolic blood pressure

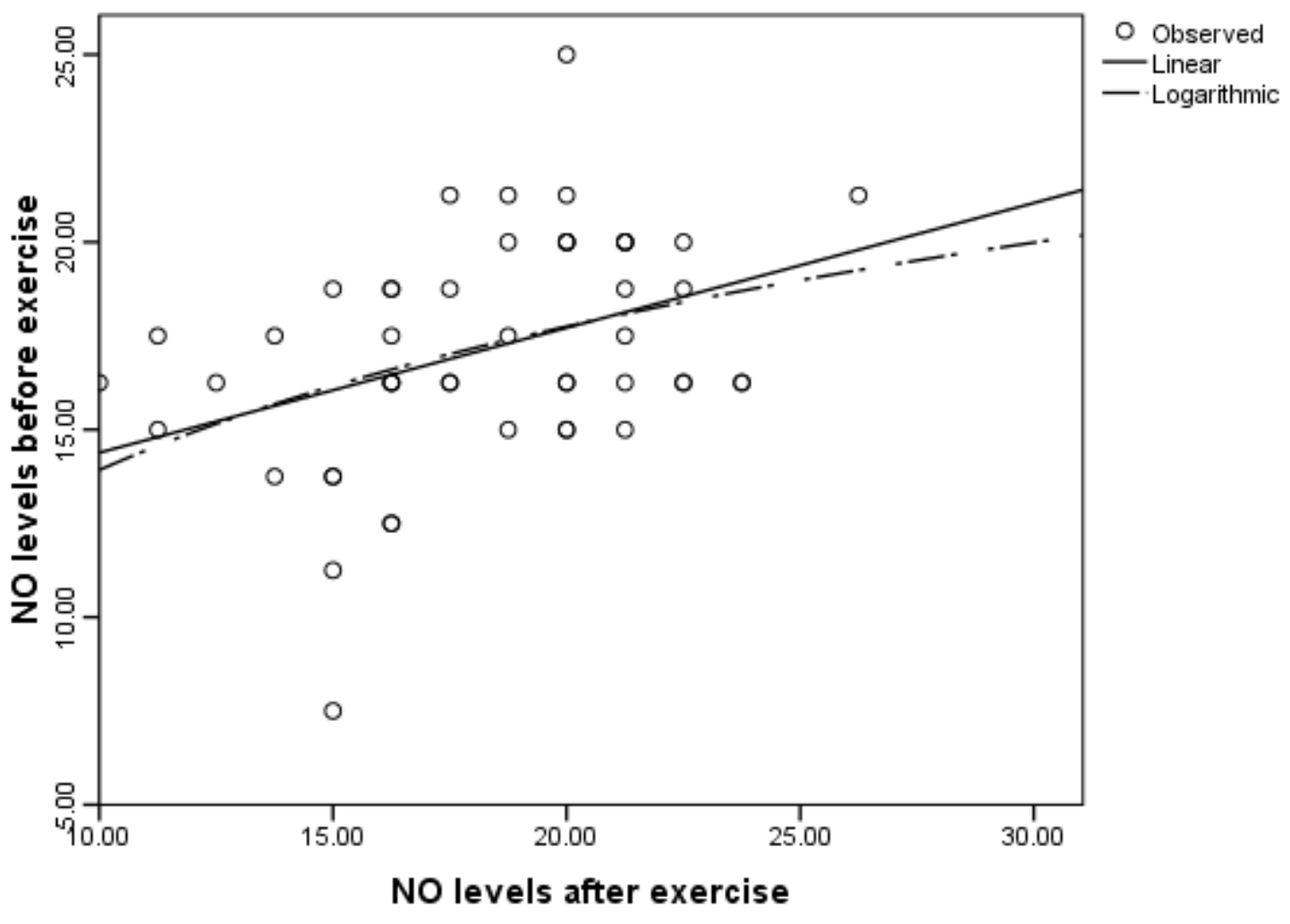

Figure 1:-Graph showing NO levels in trained athletes before and after exercise.

\section{References:-}

1. Valadoa A, Paula C. Tavares, Leonel pereira \& C. Fontes Ribeirao. Anaerobic exercise and oxidative stress Effect of the intense exercise on Nitric oxide and Malondialdehyde. International Journal of Biology and Biomedical Engineering 2007;1:26-32.

2. Powers SK and Jackson M. Exercise-induced oxidative stress: cellular mechanisms and impact on Muscle Force Production. Physiol Rev. 2008;88:1243-76. [PMCID: PMC2909187; doi: 10.1152/physrev.00031.2007]

3. MuntanéJ and Bonavida B. Special collection: Nitric oxide in cancer. Redox Biol 2015;6:505-6. [PMCID: PMC4600854 doi: 10.1016/j.redox.2015.09.038]

4. Spirlandeli AL, Deminice R, Jordao AA. Plasma Malondialdehyde as Biomarker of Lipid Peroxidation: Effects of Acute Exercise. Int J Sports Med 2014;35:14-18.

5. Dimitrios T. Analysis of nitrite and nitrate in biological fluids by assays based on the Griess reaction: appraisal of the Greiss reaction in the L-arginine/ nitric oxide area of research. J Chromatography 2007;851:51-70.

6. Yalçin AS, Kilinç A, Cobek B . Evaluation of a simple colorimetric analysis for urinary malondialdehyde determination. Pathol Lab Med Int 2009;1:23-6.

7. Min-Sung Ha, Do-Yeon Kim, YeONG-Ho BAek. EfFects of Hatha yoga eXercise on Plasma MALONDIALDEHYDE CONCENTRATION AND SUPEROXIDE DISMUTASE ACTIVITY IN FEMALE PATIENTS WITH SHOULDER PAIN. J PHYS THER SCI 2015;27:2109-12.

8. BRADY PS, BRADY LJ, UlLREY DE. SELENIUM, VITAMIN E AND THE RESPONSE TO SWIMMING STRESS IN THE RAT. J NUTR. 1979;109:1103-9.

9. Dillard CJ, Litov RE, Savin WM, Dumelin EE, Tappel Al. EfFeCts of EXercise, Vitamin E, ozone on PULMONARY FUNCTION AND LIPID PEROXIDATION. J APPL PHYSIOL. 1978;45:927-32.

10. Diaz PT, Brownstein E, Clanton TL.Effects of $\mathrm{N}$-acetylcysteine on in vitro diaphragm function are temperature dependent.J Appl Physiol 1994;77:2434-9. 
11. Kobzik L, Reid MB, Bredt DS, Stamler JS.Nitric oxide in skeletal muscle.Nature. 1994;372:546-8.

12. Balon TW, Nadler JL. Nitric oxide release is present from incubated skeletal muscle preparations.J Appl Physiol 1994;77:2519-21.

13. Kiyici F, Kishali NF. Acute effect of intense exercises on serum superoxide dismutase, catalase and malondialdehyde levels in soccer players. J Sports Med Phys Fitness. 2012;52:107-11.

14. Arslan M, IPEKCI SH, KEBAPCILAR L, ET AL., "EFFECT OF AEROBiC EXERCiSE Training ON MDA AND TNF-

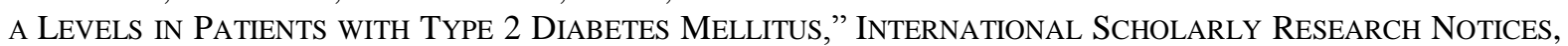
VOL. 2014, ARTICLE ID 820387, 5 PAGES, 2014. DOI:10.1155/2014/820387

15. Gomes EC, Silva AN, de Oliveira MR. Oxidants, antioxidants, and the beneficial roles of exercise-induced production of reactive species. Oxid Med Cell Longev 2012;2012:756132.

16. Steinbacher $\mathrm{P}$ AND ECKL P. ImPact of Oxidative Stress ON Exercising Skeletal Muscle. BIOMOLECULES 2015;5:356-77. [PMCID: PMC4496677; DOI: 10.3390/BIOM5020356]

17. Matsumoto A, Hirata Y, Momomura S, Fujita H, Yao A, Sata M, et al. Increased nitric oxide production during exercise. Lancet 1994;343:849-50.

18. Bode-Boger SM., Boger RH, Schroder EP, Frolich JC. Exercise increases systemic nitric oxide production in men. J. Cardiovasc. Risk 1994;1:173-8.

19. Jungersten L, Ambring A, Wall B, Wennmalm A. Both physical fitness and acute exercise regulate nitric oxide formation in healthy humans. J. Appl. Physiol. 1997;82:760-4.

20. Maeda S, Tanabe T, Otsuki T, Sugawara J, IEmitsu M, Miyauchi T et al. Moderate Regular exercise INCREASES BASAL PRODUCTION OF NITRIC OXIDE IN ELDERLY WOMEN. HYPERTENS RES. 2004;27:947-53.

21. Roberts CK, Barnard RJ, Jasman A, Balon TW. Acute exercise increases nitric oxide synthase activity in skeletal muscle. Am. J. Physiol. 1999;277:E390-E394.

22. Hirschfield W, Moody MR, OBrien WE, Gregg AR, Bryan RM Jr, Reid MBNitric oxide release and contractile properties of skeletal muscles from mice deficient in type III NOS.Am J Physiol Regul Integr Comp Physiol 2000;278:R95-R100.

23. Tidball JG, Lavergne E, Lau KS, Spencer MJ, Stull JT, Wehling M. Mechanical loading regulates NOS expression and activity in developing and adult skeletal muscle. Am J Physiol. 1998;275:C260-6.

24. Sessa WC, Pritchard K, Seyedi N, Wang J, Hintze TH. Chronic exercise in dogs increases coronary vascular nitric oxide production and endothelial cell nitric oxide synthase gene expression. Circ Res 1994;74:349-53.

25. Delp MD, Laughlin MH. Time course of enhanced endothelium-mediated dilation in aorta of trained rats. Med Sci Sports Exerc 1997;29:1454-61.

26. Tanabe T, Maeda S, Miyauchi T, et al. Exercise training improves aging-induced decrease in eNOS expression of the aorta. Acta Physiol Scand 2003;178:3-10.

27. Maeda S, Tanabe T, Miyauchi T, et al. Aerobic exercise training reduces plasma endothelin- 1 concentration in older women. J Appl Physiol 2003;95:336-41. 